\title{
AUTOGENOUS CALLO-OSSEOUS GRAFTS FOR THE REPAIR OF OSTEOCHONDRAL DEFECTS
}

\author{
SHINOBU TAKAHASHI. MASANORI OKA, YOSHIHIKO KOTOURA, TAKAO YAMAMURO
}

From Kyoto University, Kyoto, Japan

We describe a new method of biological repair of osteochondral defects. In rabbit knees an osteochondral defect was reconstructed with a callo-osseous graft made of a superficial sheet of medullary fracture callus attached to a base of cancellous bone. This was taken from the iliac bone of the same animal which had been osteotomised ten days earlier. The reparative tissues were evaluated for 24 weeks by quantitative histology, biochemical analysis of the uronic acid content, and immunohistochemical staining of collagen constituents.

The callo-osseous graft provided significantly faster and better repair of the articular surface than an untreated defect or a callo-osseous graft in which the cells had been devitalised by irradiation before transplantation.

Our findings indicate that the callo-osseous graft contributes to the repair process by providing both favourable extracellular matrices and pluripotential mesenchymal cells. Our study tested the hypothesis that early medullary callus generates hyaline cartilage instead of bone after transfer to an articular surface.

J Bone Joint Surg [Br] 1995:77-B:194-204.

Received 2 June 1994: Accepted 29 July 1994

Various experimental and clinical approaches have been tried to achieve biological repair of localised chondral and osteochondral lesions with varying degrees of success (Speer et al 1979; Salter et al 1980; Amiel et al 1985; Aston and Bentley 1986; O'Driscoll and Salter 1986; O'Driscoll, Keeley and Salter 1986, 1988; Itay, Abramovici and Nevo 1987; Homminga et al 1989, 1990; Wakitani et al 1989; Caterson and Buckwalter 1990; Dahlberg and Kreicbergs

S. Takahashi, MD, DMSc, Postdoctoral Fellow

Y. Kotoura. MD, DMSc, Associate Professor

T. Yamamuro. MD, DMSc. Professor and Chairman

Department of Orthopaedic Surgery. Faculty of Medicine. Kyoto University, 54 Shogoin-Kawaracho, Sakyo-ku, Kyoto 606-01, Japan.

M. Oka. MD. DMSc, Professor

Department of Artificial Organs, Research Centre for Biomedical Engineering. Kyoto University, 53 Shogoin-Kawaracho, Sakyo-ku, Kyoto 606-01, Japan.

Correspondence should be sent to Dr S. Takahashi at Service d'Orthopédie. Centre Hospitalier Universitaire de Nantes, Hôtel Dieu. BP 1005 44035 Nantes Cedex 01. France.

(C)1995 British Editorial Society of Bone and Joint Surgery 0301-620X/95/2946\$2.(0)
1991; Shahgaldi et al 1991; Coutts et al 1992; Gardner 1992; Moran, Lim and Salter 1992). We have attempted to develop and test a new method of articular surface reconstruction based on the multipotential nature of fracture callus.

A callo-osseous graft is a sheet of immature fracture callus and subjacent cancellous bone. It can recruit undifferentiated mesenchymal cells on to the articular surface and benefits from the secure anchorage of these cells within the callus matrix. It has a matrix which provides a scaffold for cell migration, proliferation and differentiation, rich in natural collagen with a sound base of cancellous bone. In addition, it may deliver local growth factors which are normally present in the callus matrix, and it is free from the potential immunogenicity associated with allografts and of foreign-body reactions which may be elicited by implants.

The biological purpose of the present study was to determine whether immature fracture callus would generate hyaline cartilage instead of bone when transferred to a joint surface. To assess the contribution of grafted cells independent of their matrix we studied another group of animals in which callo-osseous grafts had been irradiated before transplantation. The dose selected was within the range in which irradiated cells become incapable of proliferation but the matrix proteins are preserved unaffected (Takahashi et al 1991).

\section{MATERIALS AND METHODS}

We used 87 skeletally mature male rabbits of the Japanese strain. They were between six months and two years of age and their weight was $3509 \pm 454 \mathrm{~g}$ (SD) at the time of the first operation. They were kept in individual cages, fed with commercial food pellets and allowed free access to water. They were randomised into three groups of 29 , one of which received callo-osseous grafts, one irradiated calloosseous grafts, and the third was left with untreated defects.

Osteotomy of the iliac bone. Each animal was anaesthetised by intravenous pentobarbital sodium $30 \mathrm{mg} / \mathrm{kg}$ body-weight. The left low back area was shaved, disinfected and prepared for operation. To obtain adequate analgesia and haemostasis, $3 \mathrm{ml}$ of $0.67 \% \mathrm{w} / \mathrm{v}$ lidocaine, to which $0.0003 \% \mathrm{w} / \mathrm{v}$ epinephrine had been added, were injected intracutaneously and percutaneously at the left posterior iliac spine. A $2 \mathrm{~cm}$ oblique incision was made 

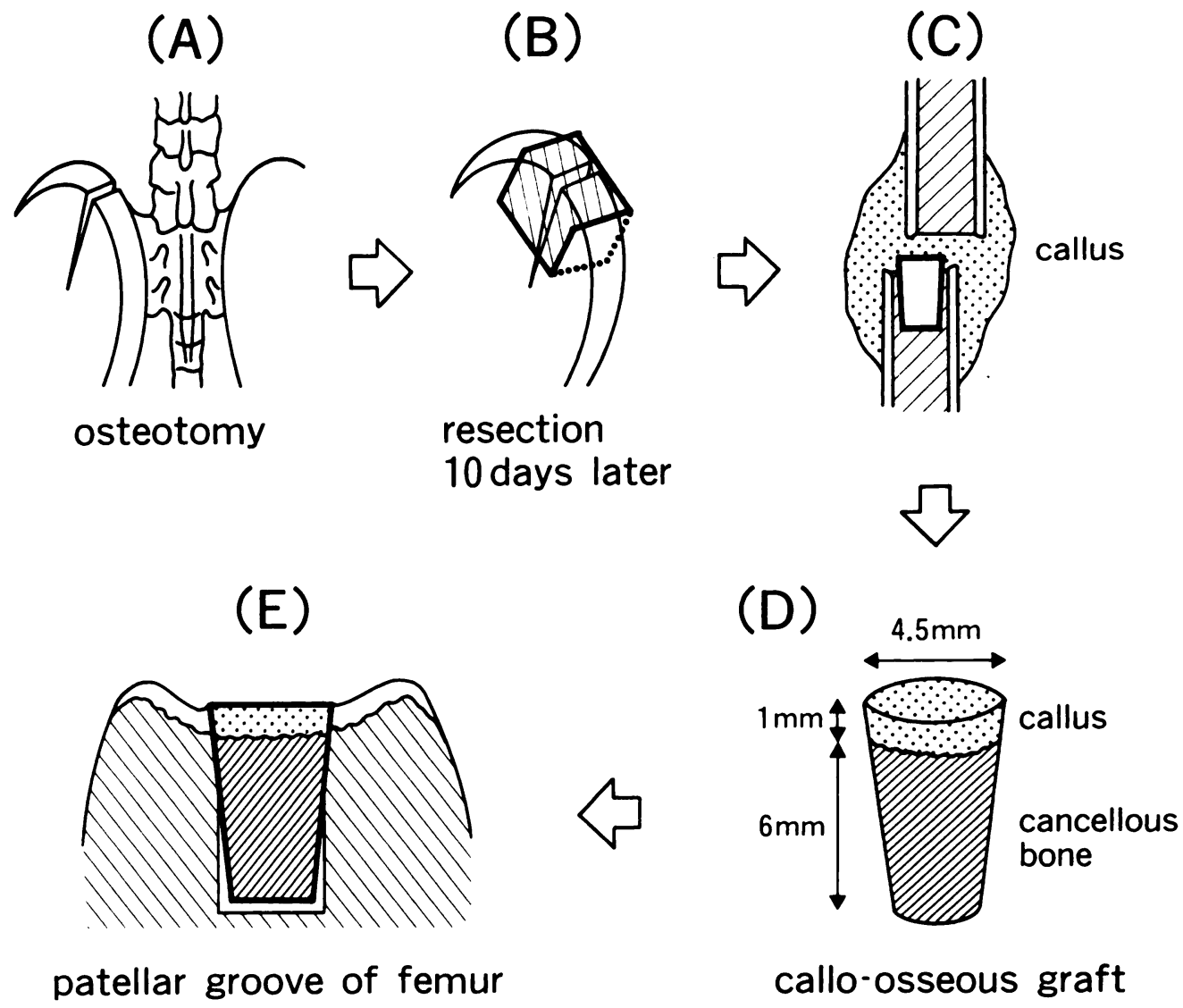

callo-osseous graft

Fig. 1

Preparation and transplantation of the callo-osseous grafts. One side of the pelvis is osteotomised (A). Ten days later the osteotomy site is excised en bloc (B). The callo-osseous graft is prepared from the medullary region of the callus and the subjacent cancellous bone (C and D). The graft is press-fit into an osteochondral defect in the patellar groove of a femur of the same animal $(E)$.

parallel to the posterior part of the iliac crest. The posterior iliac spine was then identified and the periosteum incised exactly on the spine, perpendicular to the longitudinal axis of the crest. The periosteum on the inner and outer surfaces of the iliac bone along the osteotomy line was also incised using a pointed scalpel. A flat osteotomy cut, approximately $25 \mathrm{~mm}$ deep, was made perpendicular both to the line of the crest and the inner and outer cortical surface with a $10 \mathrm{~mm}$ wide straight chisel (Fig. 1A). With the base of the bone fragments attached, the osteotomy gap was widened gently to about $2 \mathrm{~mm}$. The wound was irrigated with physiological saline, the fascia adjacent to the incised periosteum closed with nylon sutures to cover the osteotomy gap and the subcutaneous tissues and skin closed with interrupted sutures. After the operation, the animals were allowed to move around freely in their individual cages.

Preparation of the callo-osseous grafts. Ten days after osteotomy of the ilium, all the rabbits underwent a second operation under general anaesthesia. Both knees and the low back were shaved and prepared. The lidocaine/epinephrine mixture was injected around the wound and osteotomised iliac bone. An area of skin $5 \mathrm{~mm} \times 20 \mathrm{~mm}$, including the sutured wound, was excised and the iliac bone and soft tissues, including the osteotomy site, were removed en bloc (Fig. 1B), wrapped in a piece of gauze soaked with physiological saline and kept in a sterile plastic dish at room temperature until required. The wound was irrigated with physiological saline and closed as before. The iliac bone block was divided at the mid-plane of the osteotomy into two fragments. A cylindrical piece comprising cancellous bone and fracture callus was obtained from the medullary portion of each fragment (Fig. 1C) and, with care not to separate the callus from the cancellous bone, fashioned into a cylinder, approximately $4.5 \mathrm{~mm}$ in diameter and $7 \mathrm{~mm}$ thick, with a $1 \mathrm{~mm}$ layer of callus (Fig. 1D). The diameter of the callus end of the graft was made slightly larger than the other end to achieve press-fit insertion into a drill hole. Two identical callo-osseous grafts were obtained from each iliac bone block.

Irradiation of the grafts. During the second operation some callo-osseous grafts were irradiated. The iliac bone block covered with gauze soaked in saline was placed in a sterile, plastic cell-culture dish and a single $50 \mathrm{~Gy}$ dose of $10 \mathrm{MV}$ X-ray irradiation delivered by a linear accelerator used for clinical radiotherapy. An acrylic board $25 \mathrm{~mm}$ thick was used to obtain a full build-up of energy. The dose rate was $6 \mathrm{~Gy}$ per minute and the procedure took approximately nine minutes. While irradiation was in progress, the 
wound in the low back was closed and the animal was prepared for knee arthroplasty. All the grafts remained out of the rabbit for between 15 and 25 minutes whether irradiated or not.

Intra-articular transplantation of callo-osseous grafts. After the callo-osseous grafts had been prepared, the animal from which they came was placed supine. Both knees were flexed to $90^{\circ}$, and both knee areas were disinfected and prepared. A $1 \mathrm{ml}$ dose of the lidocaine/epinephrine mixture was injected subcutaneously into the medial parapatellar region which was then incised. The knee was opened and the patella dislocated laterally. The area of the patellar groove of the femur which opposed the patella exactly when the knee was flexed at $90^{\circ}$ was selected as the site for the osteochondral defect, and a hole $4.5 \mathrm{~mm}$ in diameter and $7 \mathrm{~mm}$ deep was made using an electric drill. The cartilage and subchondral bone debris were removed and the joint irrigated copiously with physiological saline. A callo-osseous graft was inserted into each defect with a press-fit such that the callus part of the graft was placed slightly higher than the surrounding articular surface (Fig. 1E). The joint was irrigated again, and the wound closed as before. In the group with untreated defects, the iliac bone block was harvested in the same way but the osteochondral defects in the knees were left ungrafted. The iliac bone blocks taken from this group were examined histologically to determine the structure of the callus and callo-osseous graft at this stage. Both knees of each animal were subjected to the same operation in all groups. After the second operation, all the animals were allowed to move freely in their individual cages. No external immobilisation or passive motion was used.

The animals were killed by an overdose of intravenous pentobarbital sodium 2,8 or 24 weeks after the second operation. Both distal femora were removed. The lateral semicircular half of the reparative tissue was dissected out with a scalpel and subjected to biochemical analysis. The remaining distal femoral tissue, including the medial half of the reparative tissue, was examined histologically.

Histological preparation. The distal femora were fixed with $10 \% \mathrm{w} / \mathrm{v}$ phosphate-buffered formalin for $\mathbf{4 8}$ hours. The lateral half of each fragment was cut off with a band saw and discarded to leave the medial half of the distal femur with its regenerated tissue, which was then decalcified with $5 \% \mathrm{w} / \mathrm{v}$ ethylenediamine tetra-acetic acid for three weeks, dehydrated with increasing concentrations of ethanol, rinsed with chloroform and embedded in paraffin. Sagittal sections $5 \mu \mathrm{m}$ were cut and stained with haematoxylin/eosin and safranin $\mathrm{O} /$ fast green. The iliac bone blocks and callo-osseous grafts made from the group with ungrafted defects were prepared similarly.

Histological grading scale. The osteochondral defects and healed tissues were scored histologically according to the grading scale devised by O'Driscoll et al (1988) which involves assessment of nine parameters of tissue regeneration: cellular morphology of the predominant tissue ( 0 to 4 points); affinity of the matrix to safranin $\mathrm{O}$ stain (0 to 3$)$; surface regularity (0 to 3 ); structural integrity (0 to 2$)$; thickness of the reparative tissue ( 0 to 2 ); bonding to the adjacent cartilage ( 0 to 2 ); cellularity ( 0 to 3 ); freedom from chondrocyte clustering ( 0 to 2 ); and freedom from degenerative changes in the adjacent cartilage ( 0 to 3 ). The full total of 24 points indicates complete regeneration of the hyaline articular cartilage.

Biochemical analysis. The superficial tissue inside the lateral semicircular part of the repaired area was removed from the distal femur with care not to include the surrounding undamaged cartilage, and its wet weight determined. The uronic acid assay was performed using a modified method based on the sulphate-carbazole reaction described by Bitter and Muir (1962). The tissue was digested with papain solution $(50 \mu \mathrm{g} / \mathrm{ml}$ of lyophilised and crystallised papain (Sigma) in $0.1 \mathrm{M}$ phosphate buffer ( $\mathrm{pH}$ 6.5) containing $0.005 \mathrm{M}$ cysteine hydrochloride warmed at $65^{\circ} \mathrm{C}$ for 30 minutes before use) for 16 hours at $65^{\circ} \mathrm{C}$. A $250 \mu$ l sample of the fluid was mixed with $100 \mu \mathrm{l} 0.2 \%$ w/v carbazole dissolved in pure ethanol to which $2.5 \mathrm{ml}$ concentrated sulphuric acid was added and the mixture heated at $100^{\circ} \mathrm{C}$ for 20 minutes. The solution was allowed to cool to room temperature and its photoabsorption at $525 \mathrm{~nm}$ measured by a photoabsorptiometer. The uronic acid concentration was calculated using the linear equation derived from the photoabsorption values of standard D-glucuronolactone solutions of known concentrations. As control samples, normal cartilage tissues from the corresponding femoral portion were obtained from six age- and sex-matched rabbits who had not undergone operation. These samples and those of the experimental rabbits were analysed simultaneously.

Immunohistochemistry. Paraffin sections $5 \mu \mathrm{m}$ thick were taken from the distal femoral medial halves and subjected to indirect immunostaining of the matrix collagens. The sections were deparaffinised with xylene, rehydrated with a decreasing concentration of ethanol and rinsed three times for five minutes each with $0.01 \mathrm{M}$ phosphate-buffered saline (PBS, pH 7.2). Sections for type-II collagen immunostaining were incubated with $2 \% \mathrm{w} / \mathrm{v}$ bovine testicular hyaluronidase (Sigma) for 30 minutes at room temperature to reduce the masking effect of the proteoglycan constituents. All the sections were pretreated for 20 minutes at room temperature with blocking solution (Histomark; Kirkegaard \& Perry Laboratories Inc, Gaithersburg, Maryland) containing normal rabbit serum and then incubated for 60 minutes at room temperature with the required anticollagen antibody at optimal dilutions in $0.01 \mathrm{M}$ PBS with $1 \% \mathrm{w} / \mathrm{v}$ bovine serum albumin. The primary antibodies used were commercially available goat polyclonal antibodies against type-I, type-II and type-III collagens (Southern Biotechnology Associates Inc, Birmingham, Alabama). The sections were rinsed three times for five minutes each with $0.01 \mathrm{M}$ PBS, treated with $0.1 \% \mathrm{w} / \mathrm{v}$ hydrogen peroxide in methanol for 20 minutes and rinsed again three times with PBS. They were then incubated with biotinylated antigoat IgG (Histo- 
mark), rinsed three times with PBS, treated for 45 minutes with streptavidin-horseradish peroxidase complex (Histomark), rinsed three times with PBS and treated for ten minutes with $0.02 \% \mathrm{w} / \mathrm{v}$ diaminobenzidine in $0.1 \mathrm{M}$ Tris buffer ( $\mathrm{pH} 7.6$ ) containing $0.005 \% \mathrm{w} / \mathrm{v}$ hydrogen peroxide. Consecutive sections were also treated with normal goat serum and otherwise immunostained identically to serve as negative controls.

Statistical analysis. The histological scores and the uronic acid content of the repaired tissues were analysed using a one-way analysis of variance. A $p$ value $<0.05$ was considered to be significant.

\section{RESULTS}

There were no wound infections. Eight animals died after the second operation. four in the callo-osseous-graft group. two in the irradiated-graft group and two in the defect group. A total of 158 joints from 79 animals were thus available for assessment.

Macroscopic appearance of the regenerated areas. Two weeks after the second operation, the defect reconstructed with a callo-osseous graft showed an irregular surface. often slightly depressed compared with the surrounding cartilage, and covered with heterogeneous, whitish, soft tissue. The appearance in the irradiated-graft group was similar, but the surface tissue was often darker or yellowish in colour. In the defect group, the surface was still markedly depressed concavely and the bottom of the defect was composed of a dark red. gel-like tissue.

After eight weeks, most of the articular surfaces of the callo-osseous grafts were flat, although the grafted area was still demarcated by a slight difference of smoothness and colour. The irradiated grafts had less smooth surfaces and occasionally bare subchondral bone was exposed. The surface of the defect group showed coexistent regenerative, cartilage-like tissue at the periphery and a depression in the centre.

At 24 weeks, the colour and surface glistening of the

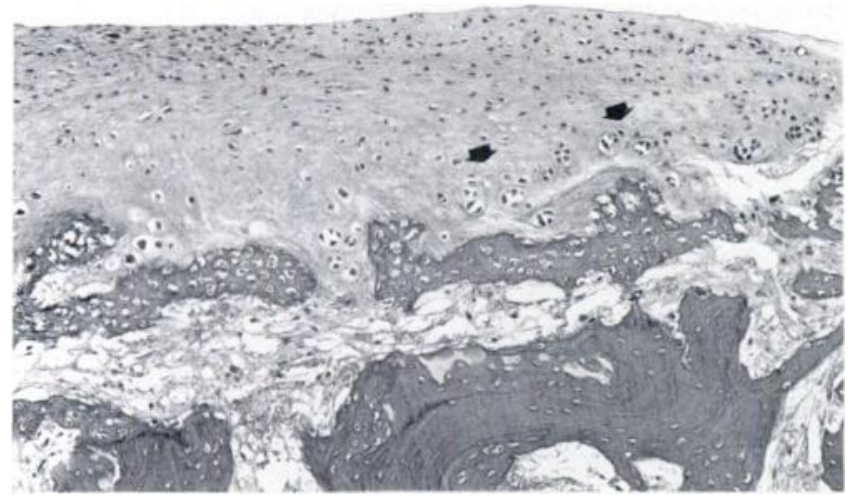

Fig. 3a regenerative tissues were different from the surrounding cartilage and the boundaries of the original defects were still visible in all cases. Many specimens in the defect group still showed a surface depression in some parts of the original defect, which was not seen in callo-osseous-graft and irradiated-graft groups.

Histological appearance. Ten-day-old callus from the iliac osteotomy had a heterogeneous composition, depending on the location. Cartilaginous callus was present exclusively on the outer surface of the cortical ends and absent within the medullary gap. The medullary callus used for the calloosseous grafts now consisted predominantly of fibrous or undifferentiated mesenchymal tissue with some woven bone which had formed near the cancellous bone by intramembranous ossification (Fig. 2).

Two weeks after transplantation, chondrocytes had appeared in the callo-osseous grafts on the superficial side of the woven bone (Fig. 3a) or between the trabeculae (Fig.

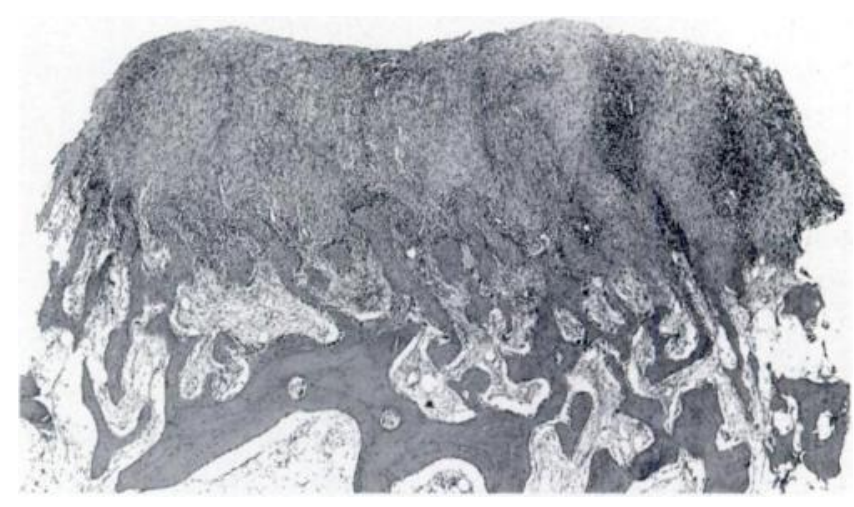

Fig. 2

A callo-osseous graft prepared for transplantation. The most superficial layer comprises undifferentiated or fibrous mesenchymal tissue. under which is a layer of woven bone, formed by intramembranous ossification (haematoxylin and eosin $\times 15$ ).

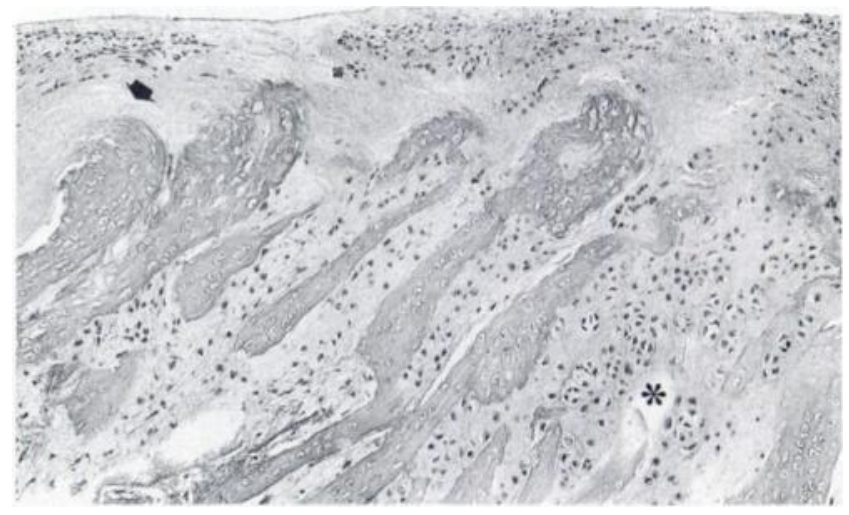

Fig. 3b

Figure 3a - Part of a callo-osseous graft two weeks after transplantation. Chondrocytes are seen on the superficial side of the woven bone (arrows). Under the articular surface are poorly differentiated cells. The bone-marrow spaces between the trabeculae are necrotic (haematoxylin and eosin $\times 40$ ). Figure $3 \mathrm{~b}$ - Two weeks after transplantation chondrocytes are seen between the columns of woven bone (asterisk). There is continuity of collagen fibres between the woven bone and callus tissue (arrow) (haematoxylin and eosin $\times 40$ ). 

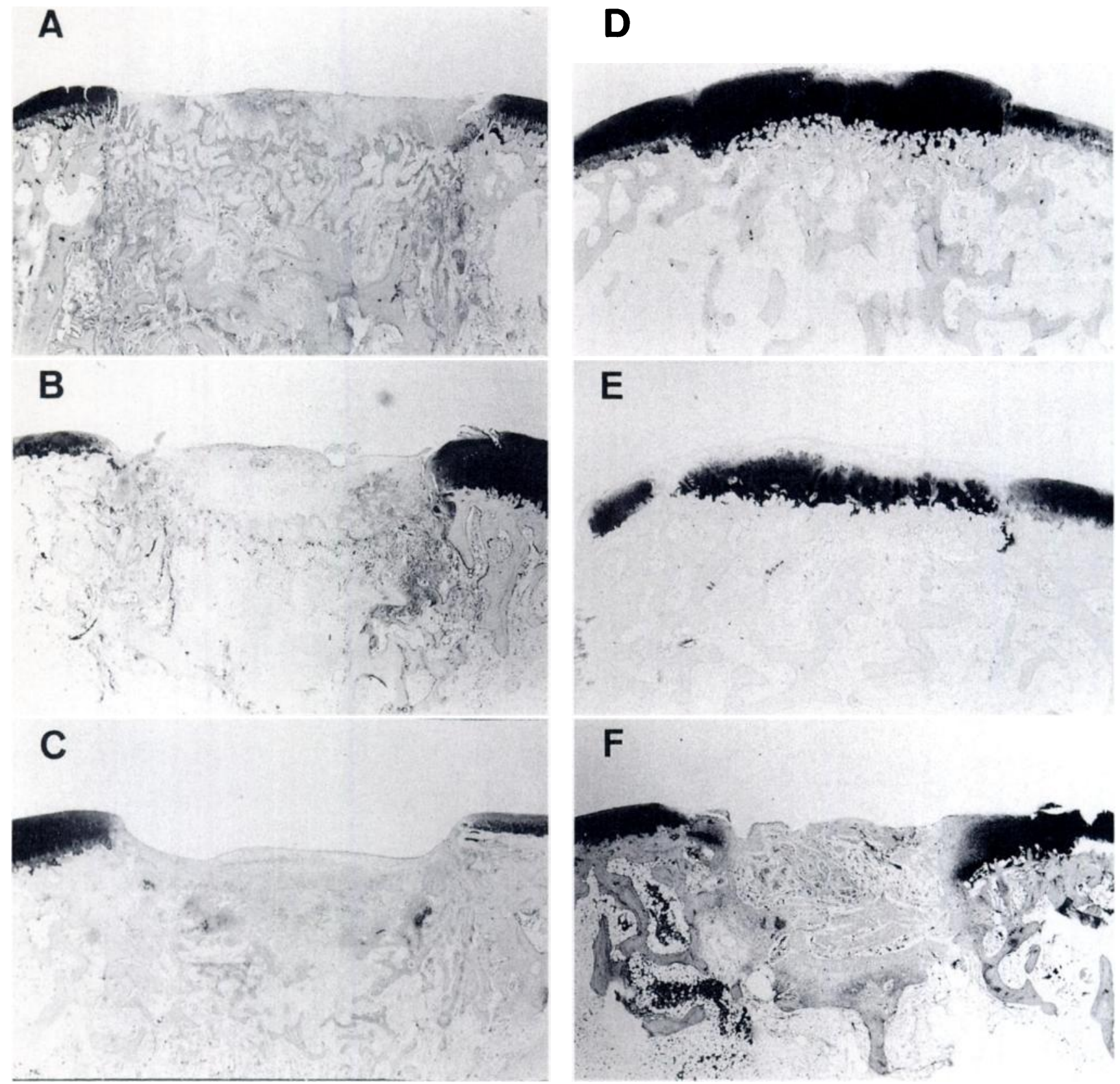

Fig. 4

A: Callo-osseous graft two weeks after transplantation. B: Irradiated callo-osseous graft after two weeks. C: Defect after two weeks. D: Callo-osseous graft after eight weeks. E: Irradiated callo-osseous graft after eight weeks. F: Defect after eight weeks (safranin 0 and fast green $\times 15$ ).

3b), but were never seen in the irradiated callo-osseous grafts at this stage. In the most superficial layer of the nonirradiated callo-osseous grafts, poorly differentiated cells with no blood vessels were observed (Fig. 4A). Eight weeks after transplantation, the proliferated chondrocytes had assumed the characteristics of hyaline cartilage, more pronounced in the middle and deep zones of the regenerative tissue (see Fig. 5). At times the thickness of the cartilage layer was greater than the surrounding normal tissue and stood proud of it (Fig. 4D). This was never seen in the defect group. Twenty-four weeks after transplantation, the superficial part of the callo-osseous graft resem- bled hyaline cartilage and in some animals a tide-mark had appeared (see Fig. 6). Substitution of the superficial tissue by bone was not seen but the thickness of the cartilage tissue tended to decrease between 8 and 24 weeks.

Two weeks after transplantation the irradiated calloosseous graft showed necrotic fibrous callus tissue on its surface with no cartilage formation (Fig. 4B). Eight weeks after transplantation there was less formation of superficial cartilage than in the non-irradiated graft, but the incorporation of subchondral cancellous bone was satisfactory irrespective of the graft irradiation (Fig. 4E). At 24 weeks the superficial layer showed a mixture of cartilaginous and 

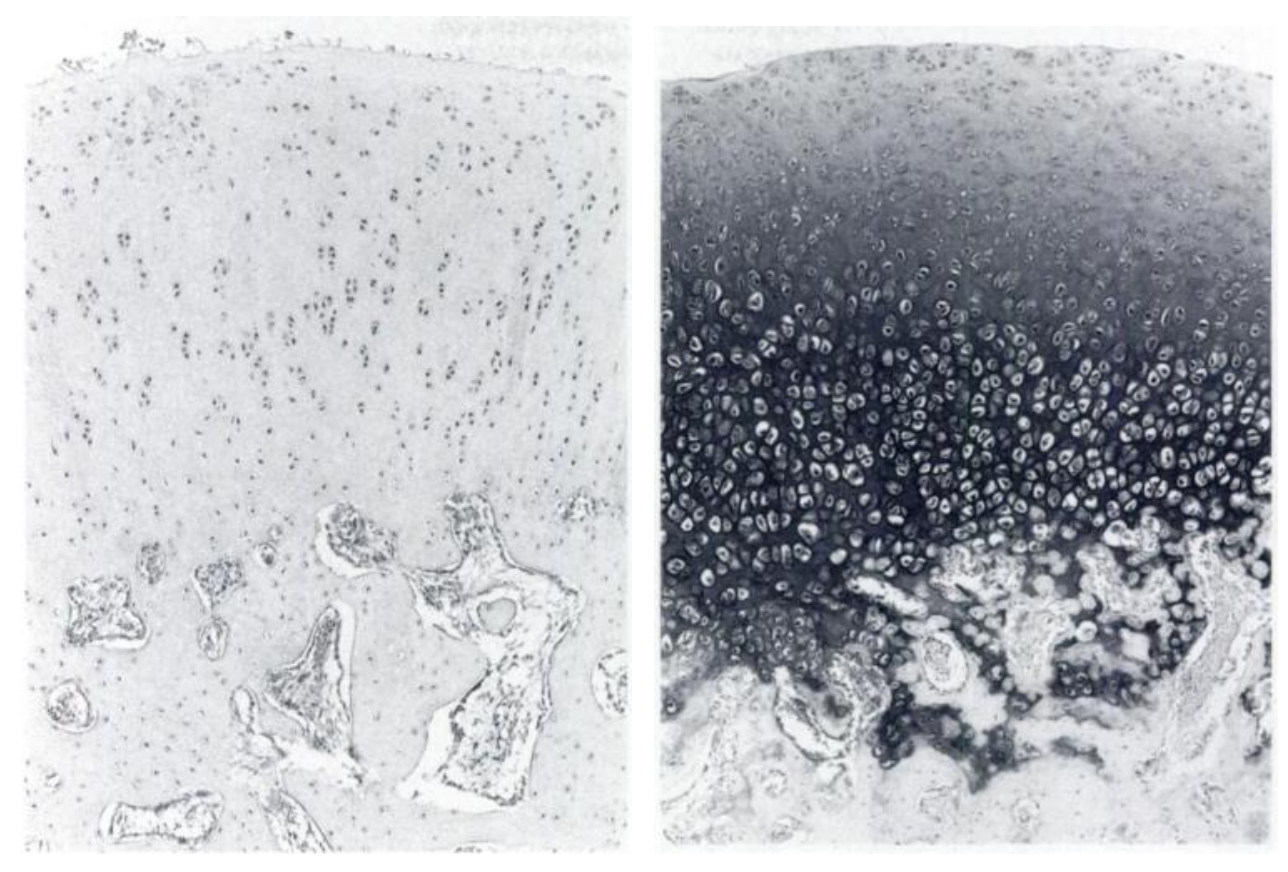

Fig. 5

Regenerated tissues in two representative callo-osseous grafts eight weeks after transplantation. In both specimens the middle and deep layers especially have hyaline cartilaginous matrix. The subchondral bone is undergoing active remodelling (left. haematoxylin and eosin $\times 40$ ), right, safranin 0 and fast green $\times 40$ ).

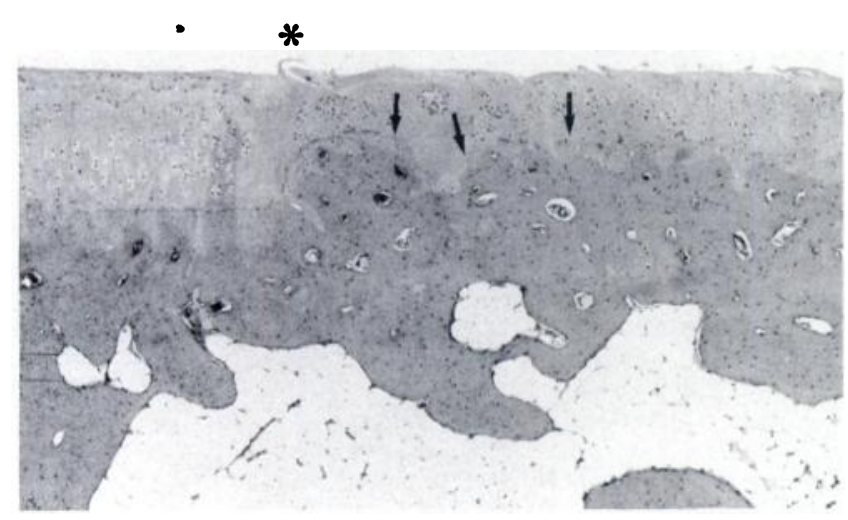

Fig. 6

A callo-osseous graft 24 weeks after transplantation. To the right of the junction (asterisk) is the repaired cartilage from the graft. The chondrocytes show decreased cellularity and irregular arrangement, but a tidemark has been formed (arrows). The repair cartilage layer is thinner than the adjacent normal cartilage (haematoxylin and eosin $\times 20$ ).

fibrous tissue under an irregular surface, with no evidence of a tide-mark in most samples.

After two weeks the site of the defect showed a marked depression with superficial loose fibrous tissue attached to the adjacent cartilage at its periphery (Fig. 4C). In the deeper zone of the defect, intramembranous new bone formation was predominant near the marrow, and cartilaginous tissue was present in only a few samples and was limited to the areas adjacent to the superficial edge of the remaining subchondral bone plate. Eight weeks after trans- plantation reparative hyaline cartilage appeared, but the central portion of the defect remained depressed and was most often occupied by fibrous or fibrocartilaginous tissue (Fig. 4F). At 24 weeks, the reparative cartilage covered most of the surface in some cases, whereas in others it was limited to patchy areas on the surface and a central depression of the subchondral bone plate still remained.

The histological grading of the reparative tissues is summarised in Table I. After two weeks, the mean total histological score of the callo-osseous-graft group was significantly higher than that of the other two groups. Eight weeks after the second operation the scores of all three groups had almost doubled but that of the callo-osseousgraft group still remained significantly higher. After eight weeks, the irradiated-graft and defect groups also differed significantly. There was little change between the total score at 8 weeks and at 24 weeks for the two graft groups; that of the defect group showed a small increase during this period. At 24 weeks, the callo-osseous-graft group still maintained a significantly higher score.

Uronic acid content. Table II shows the uronic acid content per wet weight of regenerative tissue. The mean uronic acid content of the three groups was similar after two weeks. After eight weeks, that of the two graft groups was significantly higher than that of the defect group, and the mean value of the callo-osseous-graft group tended to be higher than that of the irradiated-graft group. The mean uronic acid content for the six age- and sex-matched rabbits was $15.4 \pm 1.9 \mu \mathrm{g} / \mathrm{mg}$ wet weight. The mean values after 8 weeks were $58.2 \%, 50.3 \%$ and $33.3 \%$ of the normal control 
Table I. Histological score (mean + SD) of the reparative tissues at 2, 8 and 24 weeks after transplantation

\begin{tabular}{|c|c|c|c|c|c|c|c|c|c|}
\hline \multirow[b]{2}{*}{ Grading scale* } & \multicolumn{3}{|c|}{ After 2 weeks } & \multicolumn{3}{|c|}{ After 8 weeks } & \multicolumn{3}{|c|}{ After 24 weeks } \\
\hline & $\begin{array}{l}\text { Graft } \\
(n=14) \dagger\end{array}$ & $\begin{array}{l}\text { Irr graft } \\
(n=12)\end{array}$ & $\begin{array}{l}\text { Defect } \\
(n=14)\end{array}$ & $\begin{array}{l}\text { Graft } \\
(n=18)\end{array}$ & $\begin{array}{l}\text { Irr graft } \\
(\mathrm{n}=20)\end{array}$ & $\begin{array}{l}\text { Defect } \\
(n=18)\end{array}$ & $\begin{array}{l}\text { Graft } \\
(n=18)\end{array}$ & $\begin{array}{l}\text { Irr graft } \\
(\mathrm{n}=22)\end{array}$ & $\begin{array}{l}\text { Defect } \\
(n=22)\end{array}$ \\
\hline $\begin{array}{l}\text { Cellular morphology } \\
\text { of the predominant } \\
\text { tissue }\end{array}$ & $0.7 \pm 0.9$ & $0.1 \pm 0.3$ & $0.1 \pm 0.3$ & $2.6 \pm 1.0$ & $2.0 \pm 0.6$ & $1.4 \pm 1.2$ & $2.9 \pm 1.0$ & $2.1 \pm 0.9$ & $2.2 \pm 0.7$ \\
\hline $\begin{array}{l}\text { Safranin-O staining } \\
\text { of the matrix }\end{array}$ & $0.6 \pm 0.5$ & $0.3 \pm 0.5$ & $0.2 \pm 0.4$ & $1.9 \pm 0.8$ & $1.4 \pm 0.5$ & $1.0 \pm 0.9$ & $1.7 \pm 0.7$ & $1.6 \pm 0.5$ & $1.6 \pm 0.6$ \\
\hline Surface regularity & $0.9 \pm 0.6$ & $0.7 \pm 0.7$ & $0.1 \pm 0.2$ & $1.5 \pm 0.8$ & $1.2 \pm 0.6$ & $0.9 \pm 0.8$ & $1.4 \pm 0.7$ & $0.9 \pm 0.7$ & $1.3 \pm 0.9$ \\
\hline Structural integrity & $0.1 \pm 0.3$ & $0.0 \pm 0.0$ & $0.0 \pm 0.0$ & $0.8 \pm 0.4$ & $0.3 \pm 0.5$ & $0.1 \pm 0.2$ & $0.8 \pm 0.6$ & $0.5 \pm 0.7$ & $0.3 \pm 0.4$ \\
\hline Thickness & $0.8 \pm 0.4$ & $0.7 \pm 0.5$ & $0.0 \pm 0.0$ & $1.5 \pm 0.6$ & $1.3 \pm 0.5$ & $0.9 \pm 0.9$ & $1.2 \pm 0.5$ & $1.0 \pm 0.6$ & $1.0 \pm 0.5$ \\
\hline $\begin{array}{l}\text { Bonding to the } \\
\text { adjacent cartilage }\end{array}$ & $0.6 \pm 0.5$ & $0.6 \pm 0.5$ & $1.0 \pm 0.0$ & $1.5 \pm 0.5$ & $1.6 \pm 0.6$ & $1.2 \pm 0.7$ & $1.6 \pm 0.6$ & $1.6 \pm 0.6$ & $1.5 \pm 0.7$ \\
\hline $\begin{array}{l}\text { Freedom from } \\
\text { hypocellularity }\end{array}$ & $0.7 \pm 0.4$ & $0.3 \pm 0.5$ & $1.0 \pm 0.0$ & $1.9 \pm 0.6$ & $1.4 \pm 0.5$ & $1.2 \pm 0.7$ & $1.5 \pm 0.6$ & $1.4 \pm 0.5$ & $1.3 \pm 0.5$ \\
\hline $\begin{array}{l}\text { Freedom from } \\
\text { chondrocyte } \\
\text { clustering }\end{array}$ & $0.0 \pm 0.0$ & $0.0 \pm 0.0$ & $0.0 \pm 0.0$ & $0.3 \pm 0.4$ & $0.0 \pm 0.0$ & $0.3 \pm 0.4$ & $0.6 \pm 0.6$ & $0.1 \pm 0.3$ & $0.2 \pm 0.4$ \\
\hline $\begin{array}{l}\text { Freedom from } \\
\text { degeneration in } \\
\text { adjacent cartilage }\end{array}$ & $2.7 \pm 0.4$ & $2.4 \pm 0.5$ & $2.4 \pm 0.5$ & $2.5 \pm 0.6$ & $2.5 \pm 0.5$ & $2.2 \pm 0.5$ & $2.5 \pm 0.5$ & $1.9 \pm 0.4$ & $2.2 \pm 0.6$ \\
\hline Total score & $7.1 \pm 2.1 \ddagger$ & $5.1 \pm 2.0$ & $4.5 \pm 1.2$ & $14.4 \pm 3.6 \S$ & $11.6 \pm 1.7$ & $9.1 \pm 3.8$ & $14.3 \pm 3.7 \ddagger$ & $10.9 \pm 2.6$ & $11.5 \pm 3.4$ \\
\hline
\end{tabular}

* see text

$\dagger$ number of joints analysed

$\ddagger$ significantly higher than the irradiated-graft and defect groups with $\mathrm{p}$ values $<0.01$ for both comparisons

$\S$ significantly higher than the irradiated-graft and defect groups with $p$ values $<0.05$ and 0.01 , respectively

Table II. Uronic acid content $(\mu \mathrm{g} / \mathrm{mg}$; mean $\pm \mathrm{SD})$ of the reparative tissues

\begin{tabular}{llll}
\hline Time after transplantation & Callo-osseous graft & Irradiated graft & Defect \\
\hline Week 2 & $3.05 \pm 1.22$ & $2.84 \pm 0.88$ & $3.08 \pm 0.65$ \\
Number of joints & 14 & 12 & 14 \\
Week 8 & $8.94 \pm 3.63^{*}$ & $7.72 \pm 3.83 \dagger$ & $5.12 \pm 2.53^{* \dagger}$ \\
Number of joints & 18 & 20 & 18 \\
Week 24 & $8.34 \pm 3.27 \S$ & $6.13 \pm 2.86 \S$ & $7.02 \pm 2.10$ \\
Number of joints & 18 & 22 & 22 \\
\hline$*-*: p<0.01$ & & & \\
$\dagger-\dagger, \S \S \mathrm{p}<0.05$ & & &
\end{tabular}

value for the callo-osseous-graft, irradiated-graft and defect groups, respectively. At 24 weeks, the uronic acid content of the two graft groups tended to decrease, especially that of the irradiated-graft group, but that for the callo-osseous graft group was still higher.

Immunohistochemistry. The results of immunostaining of the regenerative tissue collagens are summarised in Table III. In the callo-osseous-graft group after two weeks there was a mixture of type-I and type-III collagen, with a small amount of type II present around the chondroid cells. After eight weeks, the reparative tissue was occupied predominantly by type-II collagen, with residual staining with antitype-III collagen chiefly near the articular surface and traces of type-I collagen (Fig. 7). Between 8 and 24 weeks,
Table III. Summary of immunohistochemical staining

\begin{tabular}{lrccc}
\hline & \multicolumn{4}{c}{ Staining to anti-collagens } \\
\cline { 2 - 5 } Tissue & Type I & Type II & Type III \\
\hline Ten-day-old medullary callus & ++ & - & ++ \\
Callo-osseous graft: & 2 weeks & ++ & + & + \\
& 8 weeks & + & ++ & + \\
& 24 weeks & + & ++ & + \\
Irradiated graft: & 2 weeks & ++ & - & + \\
& 8 weeks & ++ & ++ & + \\
& 24 weeks & + & ++ & + \\
Defect: & 2 weeks & ++ & + & ++ \\
& 8 weeks & ++ & ++ & + \\
& 24 weeks & + & ++ & + \\
\hline
\end{tabular}



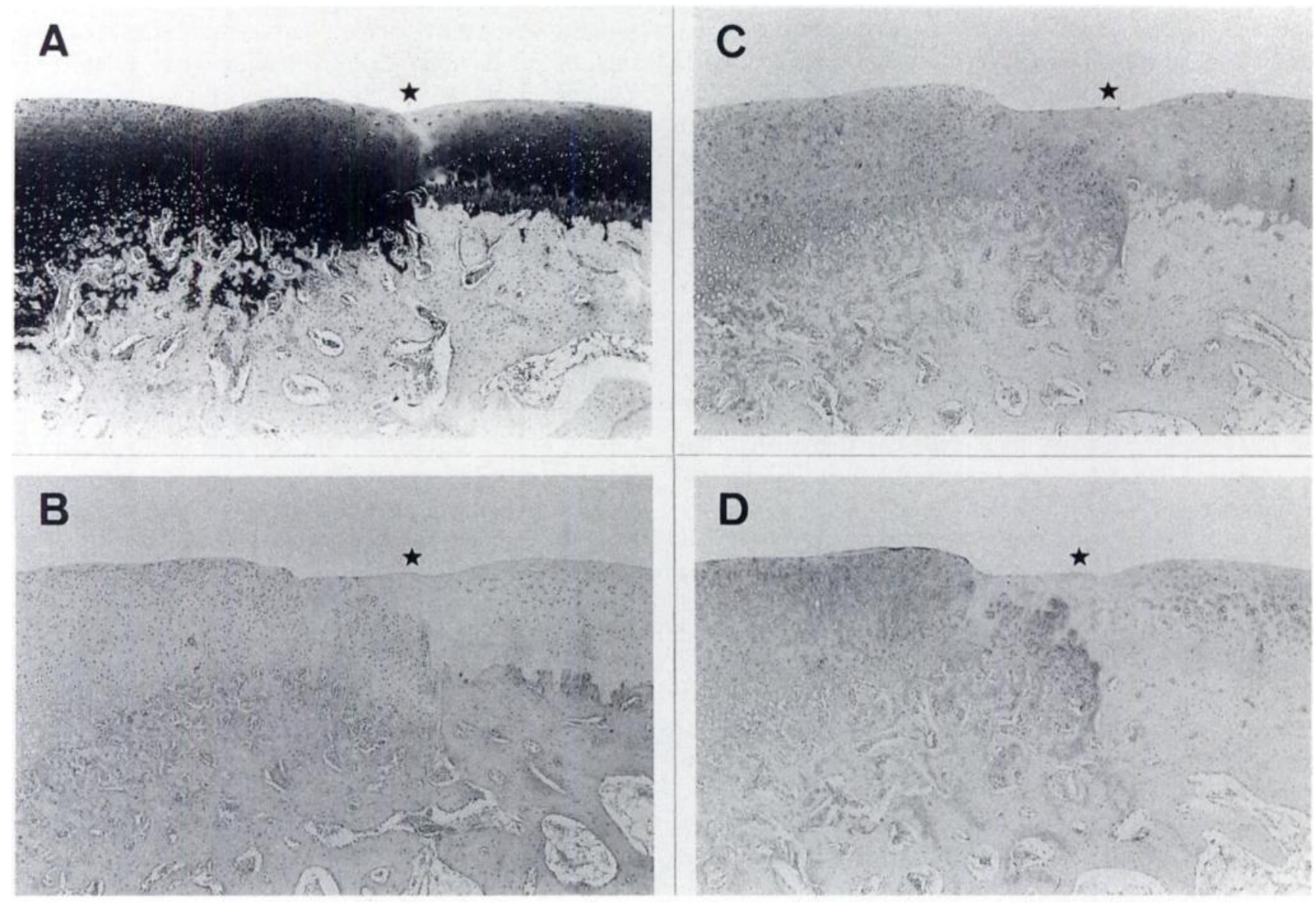

Fig. 7

Immunostaining of eight-week specimens of a callo-osseous graft. To the left of the junction (star) is the regenerated tissue, the matrix of which stained well with safranin $\mathrm{O}$ and antitype-II collagen, less so with antitype-III collagen and hardly at all with antitype-I collagen (A, safranin 0 and fast green; $B$, stained with antitype-I collagen; C, antitype-II collagen; D, antitype-III collagen $\times 18$ ).

there were no qualitative changes in the staining characteristics of the regenerative tissue. The irradiated-graft group showed a similar pattern of collagen composition, but usually with less type-II collagen. After two weeks the superficial part of the reparative tissue in the defect group consisted mainly of type-I and type-III collagen, with only occasional type II adjacent to the cancellous bone edges. After 8 weeks, the reparative matrix consisted of type-II collagen near the periphery, but the central depressed portion was composed of type-I and type-III collagen. No qualitative changes were observed at 24 weeks. At the time of transplantation the callus of the callo-osseous graft stained for type-I and type-III collagen but not type II.

\section{DISCUSSION}

Callo-osseous grafts appear to have the potential to repair osteochondral defects as shown by the histological findings, proteoglycan content and collagen composition, suggesting that medullary callus may form articular cartilage rather than bone if placed in the appropriate environment.

In vivo, active tissue turnover makes it difficult to follow the behaviour of a given group of cells. We used irradiated grafts to try to determine the contribution of the graft cells to the repair process. A single $50 \mathrm{~Gy}$ dose of irradiation has deleterious effects on remodelling, fracture healing, Haversian microvasculature and the mesenchymal cell population of rabbit bone (Sugimoto et al 1991; Takahashi et al 1994a,b) although it does not kill mature chondrocytes (Takahashi et al 1992). This level of irradiation is more than 1000 times lower than that which causes breakdown of the collagen molecule leading to immediate mechanical weakness (Bright, Smarsh and Gambill 1983) or inactivation of local growth factors, such as bone morphogenetic protein (Buring and Urist 1967). We therefore concluded that the dose used in our study would affect the cells only, and not the matrix. We have previously shown that this dose does not interfere significantly with the incorporation of a free autogenous cortical bone graft (Takahashi et al 1991).

Cells from two sources appear to have contributed to the formation of regenerative tissue in the callo-osseous graft. First, mesenchymal cells within the graft may arise both from the callus region and from the cancellous bone, including the marrow (Brighton and Hunt 1991). We assume that part of the undifferentiated or poorly differ- 
entiated mesenchymal cells in our grafts survived and underwent alterations in their differentiation pathways. Changes in the environment may have led these cells to differentiate into chondrocytes instead of osteoblasts and osteocytes. Chondrocytes already present within the graft at the time of preparation may have survived the hypoxia and changes in biomechanical conditions accompanying transplantation and proliferated as a result of clonal selection by the environment, but since virtually no cartilage callus was present in the graft their contribution would appear to be minimal.

The second source is host-derived cells which can migrate, proliferate and differentiate in the grafted matrix area. These regenerative tissue cells can derive from the marrow but not from the adjacent cartilage (DePalma, McKeever and Subin 1966; Campbell 1969; Ghadially 1983; Kim, Moran and Salter 1991; Shapiro, Koide and Glimcher 1993). Infiltration of such host cells occurred in the callus area of the callo-osseous graft since there was a marked increase in cellularity in the callus area in both the irradiated and non-irradiated grafts seen most distinctly eight weeks after transplantation.

Fracture callus is a heterogeneous tissue and its progression appears to depend on its local environment (Ketenjian and Arsenis 1975; Page, Hogg and Ashhurst 1986; Carter, Blenman and Beaupre 1988; Joyce, Jingushi and Bolander 1990; Jingushi and Bolander 1991; Cornell and Lane 1992). In optimal local conditions it will form bone, but we have shown that if callus is transferred to the environment of an articular surface it can form hyaline cartilage (Fig. 8).

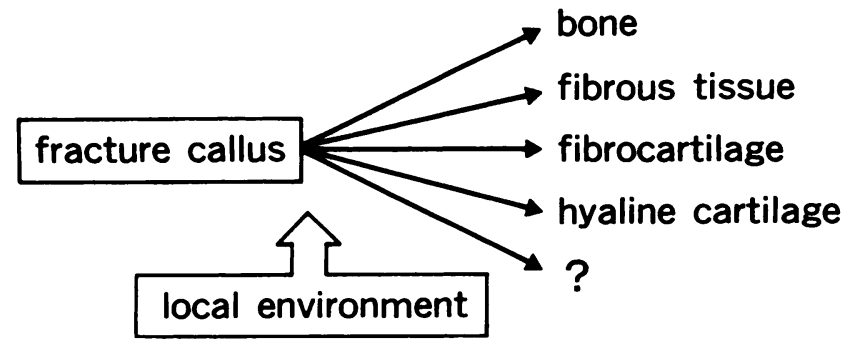

Fig. 8

Diagram illustrating the concept of multipotential fracture callus at a tissue level. The chemical, physical and biological environments cause local undifferentiated mesenchymal cells to proliferate and differentiate. The local environment of an articular surface is considered to lead to differentiation towards hyaline cartilage formation.

This supports the concept of a multipotential mesenchymal stem cell (Tonna and Pentel 1972; Ashton et al 1980; Bab et al 1984; Caplan 1991) and suggests that in the conditions of low oxygen tension and compressive loading produced in an experiment cartilage may be formed (Lane et al 1986; Carter et al 1988).

The callo-osseous graft contains extracellular matrices as well as pluripotential mesenchymal cells; these may contribute in a number of ways. They serve to anchor the mesenchymal cells securely and the callo-osseous grafts appear to have an advantage over other methods which use collagen gel or fibrin glue for fixation (Itay et al 1987; Wakitani et al 1989). The matrices may also act as a scaffold for cell migration, proliferation and differentiation. The natural healing ability of osteochondral defects depends largely on the size of the defect (Convery, Akeson and Keown 1972). The scaffold function appears to assume greater importance as the size of the defect increases. TypeIII collagen, which is a major component of the matrix of the callo-osseous graft, is considered to be the collagen through which mesenchymal cells move into position before their further differentiation into chondrocytes or other cells (Page et al 1986), which may further help repair. Another role of the matrix is the potential ability to deliver local factors such as prostaglandins, fibroblast growth factor, platelet-derived growth factor, transforming growth factor-beta, bone morphogenetic protein, insulin-like growth factor and others (Cornell and Lane 1992); it is likely that some of these local factors play a beneficial role in the transplanted graft during the initial phase.

To facilitate mechanical stimulation of the graft surface, the callo-osseous graft was placed so that its callus surface was slightly raised above the surrounding cartilage. Both knees were operated on so that the rabbits were forced to use both hind legs to move about. Continuous passive motion has been reported to exert beneficial effects on cartilage healing and neochondrogenesis (Salter et al 1980; O'Driscoll and Salter 1984) and we therefore felt that compelling the animals to move about immediately after operation would stimulate chondrogenesis in the graft.

This technique has potential clinical application. The fate of the regenerated tissues in untreated defects or those treated by other experimental methods suggests that regenerated cartilaginous tissues continue to retain some similarities to fibrocartilage (Campbell 1969; Furukawa et al 1980; Caterson and Buckwalter 1990; Coutts et al 1992; Gardner 1992) or eventually degenerate (Mitchell and Shepard 1976; Mankin 1982; Ghadially 1983; Shapiro et al 1993). In the callo-osseous graft 24 weeks after transplantation, the regenerated cartilage tissues were superior to those in the defect control group, but were inferior to normal articular cartilage. Regeneration of the superficial tangential layer was poor, which appears common to all methods of biological cartilage repair (Mitchell and Shepard 1976). Failure of this layer is considered to cause fibrillation and subsequent degeneration of entire layers (Ghadially 1983). Apart from this, Shapiro et al (1993) recently pointed out the importance of failure of bonding between the reparative and residual cartilage matrices in the development of late degenerative changes.

The question arises as to whether the callo-osseous graft will eventually ossify. In one of our preliminary experiments, identically produced pelvic osteotomies left in situ underwent complete bony union within 25 days. Our analysis of the uronic acid content of the regenerated tissues contrasts with that reported by Lane et al (1982), who 
showed a marked decrease in uronic acid content in in situ callus between 2 and 7 weeks after fracture. Dahlberg and Kreicbergs (1991) transplanted tissue in the process of heterotopic ossification into an osteochondral defect and saw no bone formation in regions adjacent to the articular surface over a 26-week period. Our data confirmed that bone formation in the callus was inhibited for at least 24 weeks after transplantation. The age of the callus used in our series was selected on the basis of some preliminary experiments. Less than 8 days after the pelvic osteotomy, the callus was too soft and easily detached from the cancellous bone; after 13 days, it had become too hard and the osteotomy surface had occasionally been modified by new bone formation.

The callo-osseous graft gave significantly faster repair by

\section{REFERENCES}

Amiel D, Coutts RD, Abel M, et al. Rib perichondrial grafts for the repair of full-thickness articular-cartilage defects: a morphological and biochemical study in rabbits. J Bone Joint Surg [Am] 1985;67-A:91120.

Ashton BA, Allen TD, Howlett CR, et al. Formation of bone and cartilage by marrow stromal cells in diffusion chambers in vivo. Clin Orthop 1980;151:294-307.

Aston JE, Bentley G. Repair of articular surfaces by allografts of articular and growth-plate cartilage. J Bone Joint Surg [Br] 1986;68-B:29-35.

Bab I, Howlett CR, Ashton BA, Owen ME. Ultrastructure of bone and cartilage formed in vivo in diffusion chambers. Clin Orthop 1984;187:243-54.

Bitter T, Muir HM. A modified unonic acid and carbazole reaction. Anal Biochem 1962;4:330-4.

Bright RW, Smarsh JD, Gambill VM. Sterilization of human bone by irradiation. In: Friedlaender GE, Mankin HJ, Sell KW, eds. Osteochondral allografis. Biology, banking and clinical applications. Boston, etc: Little, Brown, 1983:223-32.

Brighton CT, Hunt RM. Early histological and ultrastructural changes in medullary fracture callus. J Bone Joint Surg [Am] 1991;73-A:83247.

Buring $\mathbf{K}$, Urist MR. Effects of ionizing radiation on the bone induction principle in the matrix of bone implants. Clin Orthop 1967;55:225-34.

Campbell CJ. The healing of cartilage defects. Clin Orthop 1969;64:45-63.

Caplan AI. Mesenchymal stem cells. J Orthop Res 1991;9:641-50.

Carter DR, Blenman PR, Beaupre GS. Correlations between mechanical stress history and tissue differentiation in initial fracture healing. $J$ Orthop Res 1988;6:736-48.

Caterson B, Buckwalter J. Articular cartilage repair and remodeling: overview. In: Maroudas A, Kuettner K, eds. Methods in cartilage research. London, etc: Academic Press, 1990;313-35.

Convery FR, Akeson WH, Keown GH. The repair of large osteochondral defects: an experimental study in horses. Clin Orthop 1972;82:253-62.

Cornell CN, Lane JM. Newest factors in fracture healing. Clin Orthop 1992:277:297-311.

Coutts RD, Woo SL, Amiel D, von Schroeder HP, Kwan MK. Rib perichondrial autografts in full-thickness articular cartilage defects in rabbits. Clin Orthop 1992;275:263-73.

Dahlberg L, Kreicbergs A. Demineralized allogeneic bone matrix for cartilage repair. J Orthop Res 1991;9:11-9.

DePalma AF, McKeever D, Subin DK. Process of repair of articular cartilage demonstrated by histology and autoradiography with tritiated thymidine. Clin Orthop 1966;48:229-42.

Furukawa T, Eyre DR, Koide S, Glimcher MJ. Biochemical studies on repair cartilage resurfacing experimental defects in the rabbit knee. $J$ Bone Joint Surg [Am] 1980;62-A:79-89. providing both mesenchymal cells and extracellular matrices. Despite recent investigations using molecular biological techniques (Sandberg et al 1989; Jingushi and Bolander 1991; Ohta et al 1991), it is not known exactly which event determines the differentiation pathway to which a mesenchymal cell is committed and further study is needed to elucidate the regulatory mechanisms of osteogenesis and chondrogenesis. Our experimental model may be a useful tool for such research.

The authors thank Dr Y. Shibamoto, Department of Radiology, Kyoto University, for graft irradiation, and Dr H. Nishimatsu, Department of Orthopaedic Surgery, Kyoto University, for his help in surgery.

No benefits in any form have been received or will be received from a commercial party related directly or indirectly to the subject of this article.

Gardner DL, ed. Tissues. Pathological basis of the connective tissue diseases. London, etc; Edward Amold, 1992:65-119.

Ghadially FN, ed. Deep (full thickness) defects in articular cartilage. Fine structure of synovial joints. London, etc; Butterworth and Co Ltd 1983:280-306.

Homminga GN, Van der Linden TJ, Terwindt-Rouwenhorst EA, Drukker J. Repair of articular defects by perichondrial grafts: experiments in the rabbit. Acta Orthop Scand 1989;60:326-9.

Homminga GN, Bulstra SK, Bouwmeester PSM, van der Linden AJ. Perichondral grafting for cartilage lesions of the knee. $J$ Bone Joint Surg [Br] 1990;72-B:1003-7.

Itay S, Abramovici A, Nevo Z. Use of cultured embryonal chick epiphyseal chondrocytes as grafts for defects in chick articular cartilage. Clin Orthop 1987:220:284-303.

Jingushi S, Bolander ME. Biological cascades of fracture healing as models for bone-biomaterial interfacial reactions. In: Davis JE, ed. The bone-biomaterial interface. Toronto; University of Toronto Press, 1991:250-62.

Joyce ME, Jingushi S, Bolander ME. Transforming growth factor-beta in the regulation of fracture repair. Orthop Clin North Am 1990:21:199-209.

Ketenjian AY, Arsenis C. Morphological and biochemical studies during differentiation and calcification of fracture callus cartilage. Clin Orthop 1975;107:266-73.

Kim HKW, Moran ME, Salter RB. The potential for regeneration of articular cartilage in defects created by chondral shaving and by subchrondral abrasion: an experimental investigation in rabbits. $J$ Bone Joint Surg [Am] 1991;73-A:1301-15.

Lane JM, Golembiewski G, Boskey AL, Pooner AS. Comparative biochemical studies of the callus matrix in immobilized and nonimmobilized fractures. Metab Bone Dis Relat Res 1982;4:61-8.

Lane JM, Suda M, Von der Mark K, Timpl R. Immunofluorescent localization of structural collagen types in endochondral fracture repair. J Orthop Res 1986;4:318-29.

Mankin HJ. The response of articular cartilage to mechanical injury. $J$ Bone Joint Surg [Am] 1982;64-A:460-6.

Mitchell $\mathbf{N}$, Shepard $\mathbf{N}$. The resurfacing of adult rabbit articular cartilage by multiple perforations through the subchondral bone. J Bone Joint Surg [Am] 1976;58-A:230-3.

Moran ME, Lim HKW, Salter RB. Biological resurfacing of fullthickness defects in patellar articular cartilage of the rabbit: investigation of autogenous periosteal grafts subjected to continuous passive motion. J Bone Joint Surg [Br] 1992;74-B:659-67.

O'Driscoll SW, Salter RB. The induction of neochondrogenesis in free intra-articular periosteal autografts under the influence of continuous passive motion: an experimental investigation in the rabbit. $J$ Bone Joint Surg [Am] 1984;66-A:1248-57.

O'Driscoll SW, Salter RB. The repair of major osteochondral defects in joint surfaces by neochondrogenesis with autogenous osteoperiosteal grafts stimulated by continuous passive motion: an experimental investigation in the rabbit. Clin Orthop 1986;208:131-40. 
O'Driscoll SW, Keeley FW, Salter RB. The chondrogenic potential of free autogenous periosteal grafts for biological resurfacing of major full-thickness defects in joint surfaces under the influence of continuous passive motion: an experimental investigation in the rabbit. J Bone Joint Surg [Am] 1986;68-A:1017-35.

O'Driscoll SW, Keeley FW, Salter RB. Durability of regenerated articular cartilage produced by free autogenous periosteal grafts in major full-thickness defects in joint surfaces under the influence of continuous passive motion: a follow-up report at one year. J Bone Joint Surg [Am] 1988;70-A:595-606.

Ohta S, Yamamuro T, Lee K, et al. Fracture healing induces expression of the proto-oncogene c-fos in vivo: possible involvement of the Fos protein in osteoblastic differentiation. FEBS Lett 1991;284:42-5.

Page M, Hogg J, Ashhurst DE. The effects of mechanical stability on the macromolecules of the connective tissue matrices produced during fracture healing. I. The collagens. Histochem J 1986;18:251-65.

Salter RB, Simmonds DF, Malcolm BW, et al. The biological effect of continuous passive motion on the healing of full-thickness defects in articular cartilage: an experimental investigation in the rabbit. $J$ Bone Joint Surg [Am] 1980;62-A:1232-51.

Sandberg M, Aro H, Multimäki P, Aho H, Vuorio E. In situ localization of collagen production by chondrocytes and osteoblasts in fracture callus. J Bone Joint Surg [Am] 1989;71-A:69-77.

Shahgaldi BF, Amis AA, Heatley FW, McDowell J, Bentley G. Repair of cartilage lesions using biological implants: a comparative histological and biomechanical study in goats. J Bone Joint Surg [Br] 1991;73-B:57-64.
Shapiro F, Koide S, Glimcher MJ. Cell origin and differentiation in the repair of full-thickness defects of articular cartilage. J Bone Joint Surg [Am] 1993;75-A:532-53.

Speer DP, Chvapil M, Volz RG, Holmes MD. Enhancement of healing in osteochondral defects by collagen sponge implants. Clin Orthop 1979:144:326-35.

Sugimoto S, Takahashi S, Toguchida, et al. Changes in bone after highdose irradiation: biomechanics and histomorphology. J Bone Joint Surg [Br] 1991;73-B:492-7.

Takahashi S, Sugimoto M, Kotoura Y, et al. Incorporation of cortical bone autografts following intraoperative extracorporeal irradiation in rabbits. Int J Radiat Oncol Biol Phys 1991;21:1221-30.

Takahashi S, Sugimoto M, Kotoura Y, et al. Long-lasting tolerance of articular cartilage after experimental intraoperative radiation in rabbits. Clin Orthop 1992;275:300-5.

Takahashi S, Sugimoto M, Kotoura Y, et al. Long-term changes in the Haversian systems following high-dose irradiation: an ultrastructural and quantitative histomorphological study. J Bone Joint Surg [Am] 1994a;76-A:722-38.

Takahashi S, Sugimoto M, Kotoura Y, et al. The effects of intraoperative radiotherapy on bone-healing ability in relation to different doses and postradiotherapy intervals. Int J Radiat Oncol Biol Phys 1994b;30:1147-52.

Tonna EA, Pentel L. Chondrogenic cell formation via osteogenic cell progeny transformation. Lab Invest 1972;27:418-26.

Wakitani S, Kimura T, Hirooka A, et al. Repair of rabbit articular surfaces with allograft chondrocytes embedded in collagen gel. J Bone Joint Surg [Br] 1989;71-B:74-80. 